\title{
Has UK local government action improved local air quality? A Bristol case study
}

\author{
J. H. Barnes, E. T. Hayes \& J. W. S. Longhurst \\ Air Quality Management Resource Centre, \\ University of the West of England, UK
}

\begin{abstract}
In 2013, the UK exceeded the EU limit value for nitrogen dioxide $\left(\mathrm{NO}_{2}\right)$ annual mean at 31 of its 43 zones and agglomerations. Current government predictions are that full compliance will not be achieved until after 2030, with $65 \%$ zones still expected to be exceeding in 2020. In February 2014, the European Commission launched legal proceedings against the UK for its failure to cut excessive levels of $\mathrm{NO}_{2}$. However, there is an increasing onus on local authorities to manage air pollution locally and a legal threat in the Localism Act 2011 that may make them liable for any EU fines. This research has examined Local Air Quality Management (LAQM) reports and monitored concentrations of $\mathrm{NO}_{2}$ over the last 14 years for all local authorities with exceedances due to road traffic and, as previously reported to this conference series, found that there is insufficient appropriate data available to evaluate the LAQM process as a whole on this basis. Instead, six case study local authorities, for which sufficient data were available, were individually evaluated to determine whether any action plan measures could be associated with changes in local $\mathrm{NO}_{2}$ concentrations. This paper describes the methodology and findings with respect to the implementation of action plan measures, using Bristol City Council as an example. It examines some of the challenges of quantifying air quality impacts and attributing changes to implementation of measures, and makes recommendations for improvements to UK air quality management.

Keywords: LAQM, action plans, local government, $\mathrm{NO}_{2}$, air quality objectives, limit values, traffic measures, local transport plans.
\end{abstract}




\section{Introduction}

\subsection{Local Air Quality Management}

The first national Air Quality Regulations, published in December 1997 following the 1995 Environment Act, established health-based objectives for eight air pollutants, including nitrogen dioxide (Great Britain [1]). These objectives anticipated the limit values prescribed in the European Air Quality Framework Directive (96/62/EC) and subsequent daughter Directives (1999/30/EC, 2000/69/EC, 2002/3/EC), and the national Air Quality Strategy set out the government's approach to meeting them (Department of the Environment [2]). Responsibility for improving air quality fell inter alia to local authorities through the Local Air Quality Management (LAQM) regime (Department for the Environment, Transport and the Regions [3]). LAQM is the process by which local authorities in the UK review and assess air quality in their municipalities and implement action plans to remediate any local exceedances of the national objectives. The principle behind this subsidiarity approach is that sources are best managed at the lowest administrative level to ensure resources are efficiently and proportionately targeted taking account of local conditions; "Action should be taken to improve air quality at the most appropriate level, be it international, European, national or local" (Department of the Environment [2]).

At the time of the initial 1997 Strategy the UK government did not foresee how intractable and widespread the problem of traffic pollution would become. The 1997 Air Quality Strategy stated that universally applied policies should be sufficient to achieve the air quality objectives for most of the country and that the role of LAQM should be in supplementing and "fine tuning" central policies at local hotspots where national measures would be too blunt or expensive (Department of the Environment [2]).

In 2013, the UK exceeded the EU limit value for nitrogen dioxide $\left(\mathrm{NO}_{2}\right)$ annual mean at 31 of its 43 zones and agglomerations (38 not including the Margin of Tolerance) (Defra [4]). Current government predictions are that full compliance will not be achieved until after 2030 , with $65 \%$ zones still expected to be exceeding in 2020, five years after the permitted time extension period ended (Defra [5]). These estimates have been revised upwards based on the release of new vehicle emission factors which take account of the discrepancies identified between the Euro emission standards for new vehicles and their real-world usage, but with the expectation that the most recent Euro 6 vehicles would show an improvement in emissions reduction. A recent report from the International Council on Clean Transportation Europe [6], however, suggests that preliminary results are not promising with "the average, on-road emission levels of $\mathrm{NO}_{\mathrm{x}}[\ldots]$ estimated at 7 times the certified emission limit for Euro 6 vehicles". In February 2014, the European Commission launched legal proceedings against the UK for its failure to cut excessive levels of $\mathrm{NO}_{2}$.

The failure of national action to achieve the necessary reduction in $\mathrm{NO}_{2}$ places an increasing onus on local authorities in the UK to assist the government with the achievement of the EU limit values through LAQM. Given the limited resources 
and powers that local government has available for dealing with road traffic emissions, the LAQM process has received criticism for its ineffectiveness in achieving significant improvements in local air quality. In addition, local authorities may be liable for any fines resulting from the European Commission's legal proceedings against the UK government under the Localism Act 2011 [7].

\subsection{Local air quality action planning}

Air quality action planning is the means by which local authorities in the UK are required by central government to set out their intentions for working towards meeting national air quality objectives. The first Air Quality Action Plans (AQAPs) were submitted in 1999/2000 and now some 60\% of local authorities have declared one or more Air Quality Management Areas (AQMAs), primarily for traffic-related pollutants $\left(\mathrm{NO}_{2}\right.$ and $\left.\mathrm{PM}_{10}\right)$. Despite the preparation of over 400 draft and final AQAPs over the last decade, reviewers have stated there is no evidence that any traffic-related AQMAs have been revoked solely on the basis of AQAP implementation (Moorcroft and Dore [8]).

\subsection{Research statement}

This research sets out to evaluate the effectiveness of the local authorities' Air Quality Action Planning, as evidenced over the last 14 years, as a means to improve local air quality and thereby to assist the UK government in meeting the $\mathrm{EU}$ annual mean limit value for $\mathrm{NO}_{2}$ (Barnes et al. [9]). Based on experience to date, the research statement is as follows:

Local Air Quality Action Plans are not successful in terms of reducing local concentrations of $\mathrm{NO}_{2}$ and therefore Local Air Quality Management will not achieve the annual mean UK air quality objective and will therefore not make an effective contribution to meeting the relevant EU limit value.

The methodological approach for this research is summarised in Figure 1, with the subject of this paper focusing on Steps 2 and 3. which address the second of two research objectives (Objective 2: Evaluate whether the measures included in the Air Quality Action Plans produced following Round 1 are being achieved and whether implementation is contributing to an improvement in local nitrogen dioxide concentrations. (Objective 1 has been addressed in research previously presented to this conference series (Barnes et al. $[9,10]$ ).

\section{Methodology}

\subsection{Criteria for selecting AQMAs/local authorities}

The methodological approach (Figure 1) was to identify changes in local (road contribution) $\mathrm{NO}_{2}$ over the period of the implementation of Air Quality Action Plans (AQAPs), the implementation of measures in related AQAPs, and to assess any correlative relationship between them. It was therefore necessary to identify those local authorities and respective AQMAs with valid monitoring sites and $\mathrm{NO}_{2}$ 
Step 1 - assess significant changes in road-contribution nitrogen dioxide within AQMAs against Round 1 baseline

\begin{tabular}{|c|c|c|}
\hline $\begin{array}{l}\text { a) Identify AQMAs for traffic-related } \\
\mathrm{NO}_{2} \text { annual mean objective resulting } \\
\text { from Round } 1 \text { in England }\end{array}$ & $\begin{array}{l}\text { b) Establish Round } 1 \text { baseline road- } \\
\text { contribution } \mathrm{NO}_{2} \text { within AQMAs }\end{array}$ & $\begin{array}{l}\text { c) Establish road-contribution } \mathrm{NO}_{2} \text { for } \\
\text { subsequent years }\end{array}$ \\
\hline \multicolumn{3}{|c|}{ Step 2 - assess the implementation of local Action Plan measures } \\
\hline $\begin{array}{l}\text { a) Identify original Round } 1 \text { Action Plan } \\
\text { for AQMAs identified in Step } 1\end{array}$ & $\begin{array}{l}\text { b) Identify subsequent iterations of } \\
\text { AQAPs and annual AQAP Progress } \\
\text { Reports }\end{array}$ & $\begin{array}{l}\text { c) Determine progress in } \\
\text { implementation of AQAP measures }\end{array}$ \\
\hline \multicolumn{3}{|c|}{$\begin{array}{l}\text { Step } 3 \text { - Determine whether there is any relationship between changes in local } \\
\text { road-contribution } \mathrm{NO}_{2} \text { (Step 1) and implementation of AQAP measures (Step 2) }\end{array}$} \\
\hline $\begin{array}{l}\text { a) Determine temporal associations } \\
\text { between implementation of AQAP } \\
\text { measures and changes in local road- } \\
\text { contribution } \mathrm{NO}_{2}\end{array}$ & $\begin{array}{l}\text { b) Determine spatial associations } \\
\text { between implementation of AQAP } \\
\text { measures and changes in local road- } \\
\text { contribution } \mathrm{NO}_{2}\end{array}$ & $\begin{array}{l}\text { c) Identify trends across all Round } 1 \\
\text { baseline AQMAs included in the final } \\
\text { sample }\end{array}$ \\
\hline
\end{tabular}

Figure 1: Methodological flow diagram.

annual mean data relevant to their AQMAs, and that have also published AQAPs and subsequent annual AQAP Progress Reports (AQAP PRs) to enable the implementation of measures to be assessed. A series of criteria were established to identify those local authorities and AQMAs with the information required to apply the methodological approach (Figure 2) (Barnes et al. [9]).

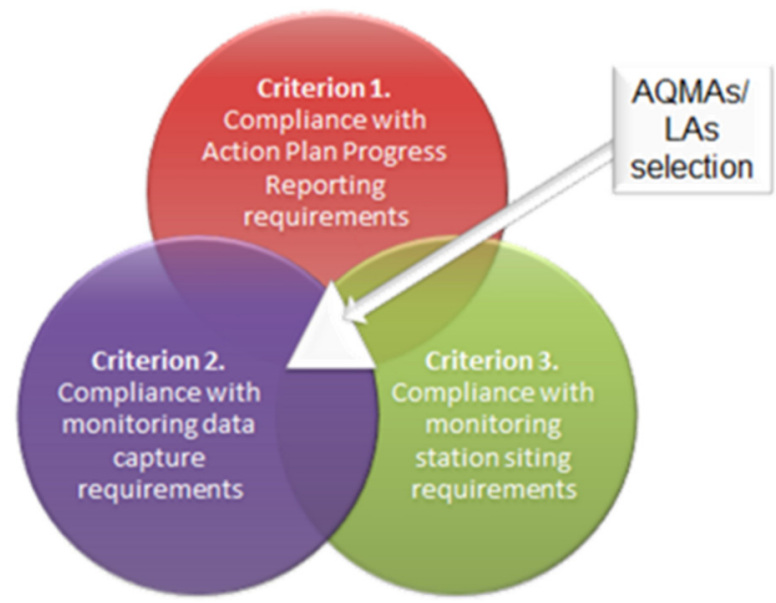

Figure 2: Criteria used to identify local authorities/AQMAs used in this study. 


\subsection{Case studies}

The criteria presented in Figure 2 resulted in the identification of eight AQMAs in six local authorities (i.e. 5\% AQMAs and 7\% local authorities that had declared AQMAs from Round 1):

- Barnsley Metropolitan Borough Council (Barnsley AQMA)

- Bristol City Council (Bristol AQMA)

- Leicester City Council (Leicester AQMA)

- Oxford City Council (Oxford AQMA)

- Sandwell Metropolitan Borough Council (Great Barr NW, Great Barr South, Great Barr SW)

- City of York Council (York AQMA)

This paper describes the methodology relating to all six case studies, and presents the results of the AQAP analysis in the Bristol AQMA as an example.

\subsection{Comparing action plans}

The sample of local authorities were selected, in part, because they complied with the Action Plan Progress Reporting requirements (Criterion 1) (i.e. AQAPs published pre-1/1/2006 and revised AQAPs, AQAP PRs or Updating and Screening Assessments (USAs) containing AQAP PRs published in 2009 or later). The purpose of this criterion was to enable an examination of the measures included in the AQAPs and the progress made in implementing them (Barnes et al. [9]).

\subsubsection{Implementation of AQAP measures}

To address the first part of Objective 2, whether measures included in the AQAPs are being achieved, the AQAPs of the case study local authorities were reviewed and recorded, together with the implementation date for those measures that were either fully or partially complete. Using the latest available progress report, measures were assessed to be 'Completed', 'Ongoing', 'Not implemented' or 'No longer reported'. Measures were compared between local authorities and against the changes in local contribution $\mathrm{NO}_{2}$ identified previously (Barnes et al. [10]).

\section{Results}

\subsection{Case studies}

\subsubsection{Bristol CC (Bristol AQMA)}

Bristol CC is a Unitary Authority in the south-west of England. Despite being Unitary, Bristol $\mathrm{CC}$ has retained links with its neighbouring authorities (Bath and North East Somerset, North Somerset and South Gloucestershire Councils) as the West of England Local Enterprise Partnership, including in the production of Joint Local Transport Plans. Bristol CC has a population of approximately 428,200 (and more than 1 million in the larger urban area). The original AQMA was declared on $1^{\text {st }}$ May 2001 (amended slightly in 2003) to cover the City Centre (including 


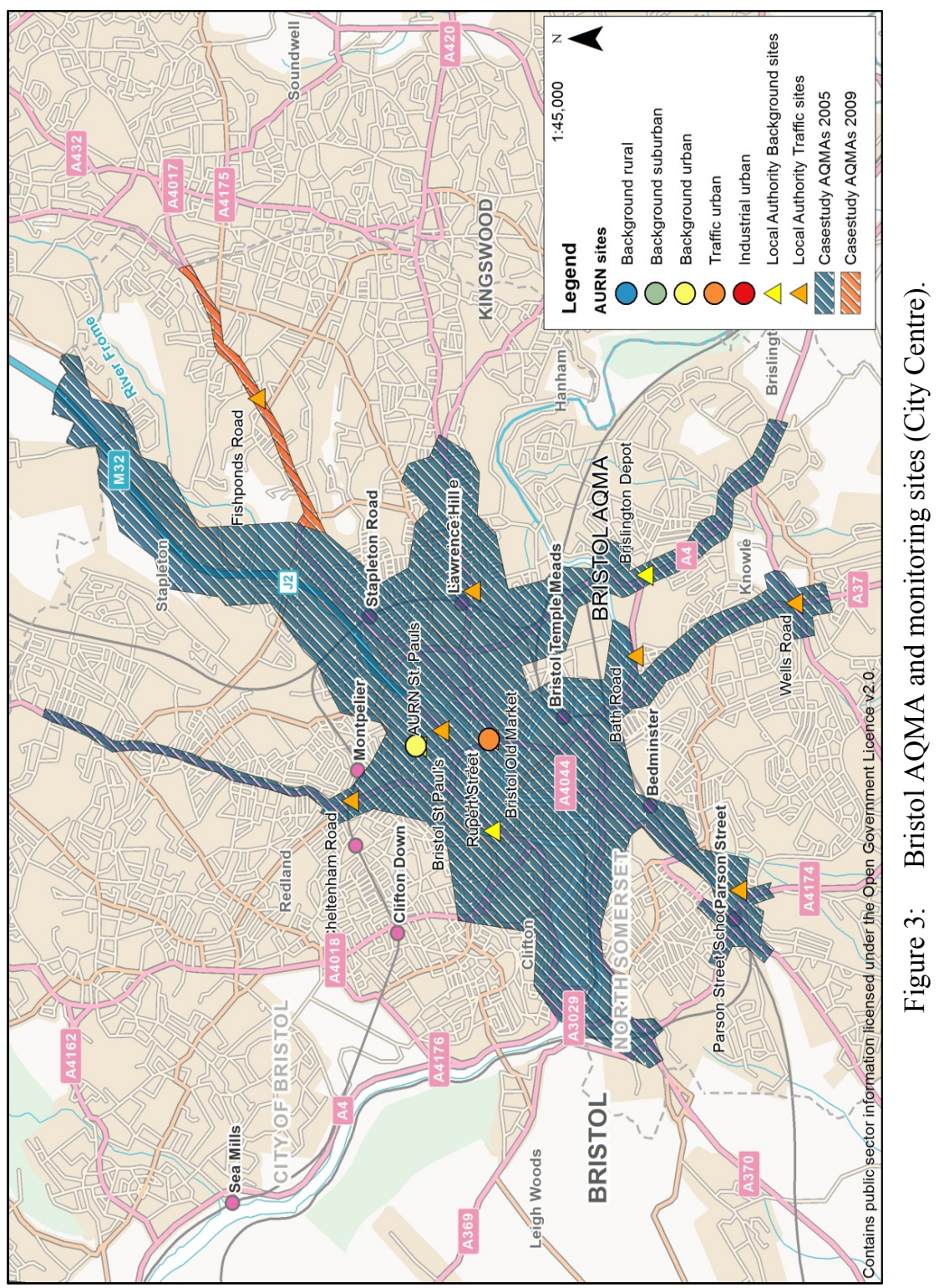


the main radial roads). In 2008, the City Centre AQMA was extended to the northeast (Figure 3). According to the AQAP the main source of NOx emissions is road traffic $(70 \%)$ with cars and taxis contributing the largest proportion $(39 \%)$ due to the large proportion of these vehicles on the roads.

\subsection{Implementation of AQAP measures}

The Bristol Local Transport Plan (LTP) was submitted in July 2000 and included a Local Air Quality Strategy as an Appendix and a draft framework for the AQAP in anticipation of the AQMA. The AQAP (published in April 2004) considered 56 measures, including six that were not considered cost effective as an air quality measure, 23 that were considered to be adequately covered in the LTP or other policies and 27 LTP 'top-up' or new measures. While some of the 23 LTP measures were reported in the LTP Annual Progress Reports, many were not explicit, e.g. 'Parking information', and others, e.g. 'Powered two-wheelers' were included in the Joint LTP (JLTP2) 2006/7-2010/11.

In addition to the 27 measures initially included in the 2004 AQAP, a further measure (Bus NOx emissions Reduction) was added in 2012 following receipt of $£ 60,000$ funding from Defra to reconfigure the engine management software on Euro IV buses to bring them up to Euro V standard.

Of the 28 measures only one (14 M32 (motorway) Management) was considered complete by 2013 following introduction of a bus lane and speed limit reduction. A further eight measures were not implemented, either due to a lack of funding, failing feasibility or cost-effectiveness tests, or were just no longer reported; 21 (sub-)measures were either on-going or included as other measures.

Amongst the measures that were considered to be on-going, there had been a good deal of progress made. For example, take-up of Travel Plans by $96 \%$ of Local Education Authorities in the AQMA; delivery of $£ 22$ million Cycling City Project; establishment of a Freight Consolidation Centre Scheme serving Bristol and neighbouring Bath; and the introduction of an Enhanced Traffic Control Centre. There were also a number of site-specific measures implemented, including Showcase Bus Routes on the A420 corridor (completed 2007), A370 Greater Bristol Bus Network (GBBN) route, A432 Fishponds Road, A4018 and A4 Bath Road corridors (completed March 2012).

\subsubsection{Relationship between AQAP and monitoring data}

The Newfoundland Road Police Station site was initiated to measure the effect of the Cabot Circus development, though sited at the end of the M32 motorway it is also subject to changes in traffic emissions relating to the M32 Management. Cabot Circus was completed in 2008 and the bus lane and speed restrictions were introduced to the southern end of the M32 in 2009. Marginally higher concentrations of local $\mathrm{NO}_{2}$ were recorded in 2009, but in subsequent years roadside concentrations have fallen, reversing a steady increase in concentrations to that point.

Monitoring at Bath Road was intended to assess the impact of a proposed 10,000 seat multi-purpose indoor arena for sports, music conferences and other events and in part as a mixed-use development providing a leisure and 
entertainment destination. This proposal was subsequently withdrawn. Road and junction bus prioritisation improvements as part of the GBBN scheme were completed on the A4 Bath Road corridor in 2012. Local concentrations of $\mathrm{NO}_{2}$ have fallen markedly in 2012 following an upward trend until this date. Concentrations at Bath Road were below the $40 \mu \mathrm{g} / \mathrm{m}^{3}$ objective in 2011 and 2012 and this monitor has now been discontinued.

Parson Street School exhibited slightly increasing local concentrations of $\mathrm{NO}_{2}$, until 2012 when concentrations dropped considerably. This may be in part due to proposed GBBN changes to the Parson Street Gyratory which were completed in March 2012.

Wells Road was also subject to improvements under the GBBN scheme which were also completed in March 2012. The Wells Road site showed a significant downward trend $(\hat{\beta}=-1.743, t=-2.997, d f=4, p=0.040$, two-sided $)$ with markedly reduced concentrations of local $\mathrm{NO}_{2}$ since 2010, and lower concentrations again in 2012. Total Roadside concentrations at this site are now just above the $40 \mu \mathrm{g} / \mathrm{m}^{3}$ objective.

GBBN corridor works were also completed on the A420 corridor in 2007. The Shiner's Garage site was established to determine the impact of this bus showcase route. Local $\mathrm{NO}_{2}$ concentrations steadily increased since 2007, however lower concentrations were recorded in 2012. Total Roadside concentrations are just above the $40 \mu \mathrm{g} / \mathrm{m}^{3}$ objective, but the site was discontinued in January 2013.

The most significant downward trend was found at Rupert Street, which has shown a steady reduction in local $\mathrm{NO}_{2}$ since $2008(\hat{\beta}=-2.857, t=-5.283, d f=4$, $p=0.006$, two-sided). Though it is difficult to identify any specific measure that may have had this effect, the Enhanced Traffic Control Centre, which was operational from September 2008, may have helped improve traffic flows and reduce congestion. There may also have been a knock-on contribution from the M32 Management giving a similar effect from 2009.

No significant trend was identified for Bristol Old Market; with only four measurements available on which to calculate a trend in local $\mathrm{NO}_{2}$ concentrations (2007-2010), concentrations fluctuated between $30 \mu \mathrm{g} / \mathrm{m}^{3}$ and $33 \mu \mathrm{g} / \mathrm{m}^{3}$. Bristol Old Market is situated close to the bottom of the A420 but, like Shiner's Garage located further to the east on this route, there has been no significant improvement in local $\mathrm{NO}_{2}$ at this site. The site was disaffiliated from the government's monitoring network in August 2012 and was discontinued from January 2013. Given the annual mean $\mathrm{NO}_{2}$ exceedances at both Bristol Old Market and Shiners' Garage it is unfortunate that these sites were discontinued.

\section{Discussion}

\subsection{Comparing action plans}

Finding and extracting the relevant data from the reports was normally straightforward, however, it was sometimes hard to trace progress with measures where there were no (or inconsistent) references, where headings or details changed or where reporting on specific measures simply ceased. There was also a 
strong degree of overlap between some measures, which were occasionally merged in later reports. Frequent reference to unexplained acronyms also required some additional investigation to determine the nature of the measure. In the majority of cases, it was not necessary to refer to other reports, e.g. Local Transport Plans, as, if the AQAP and LTP had been integrated, the AQAP section was usually reported as a standalone chapter or document. For Bristol CC, however, the AQAP only included reference to additional measures to the LTP, and so it was necessary to try to extract air quality relevant measures from the LTP as well. This was more challenging as air quality was not necessarily explicitly considered in the LTPs.

\subsubsection{Bristol City Council (Bristol AQMA)}

The distribution of Traffic Urban monitoring sites across Bristol City Centre has presented an informative representation of the variability of $\mathrm{NO}_{2}$ concentrations and trends in this urban area. They have also enabled some insight into the impacts of some of the site-specific measures implemented (or part-implemented) in the AQAP. The findings have been conflicting in some cases, with decreasing concentrations associated with improvements to the GBBN in some areas, but not others (e.g. A420 route), suggesting that there may be other confounding factors affecting these sites - unfortunately, since both the Shiner's Garage and Bristol Old Market sites have since been discontinued, continued assessment of this situation is not possible at these locations. The M32 Management also appears to have had a beneficial impact on $\mathrm{NO}_{2}$ concentrations where it enters the city, but there are numerous non-site specific measures, and measures included exclusively in the LTP that may have contributed to improvements in air quality across the City Centre and Greater Bristol Area. Air quality and transport planning appear to have been well-integrated with the publication of Joint-LTPs providing a coordinated approach to both transport and air quality management across Bristol and its neighbouring authorities.

\subsection{Summary of case studies}

In all of the case studies it was difficult to link implementation of AQAP measures with reductions in local contribution $\mathrm{NO}_{2}$. Various reasons for this were identified in the different case study local authorities.

Representativeness of monitoring sites has been a recurrent theme with the Traffic Urban site in Barnsley AQMA, the Background Urban site in Leicester AQMA and both Traffic Urban and Background Urban sites in the Sandwell (Great Barr) AQMAs not considered to be representative of their respective AQMAs, despite meeting the Criterion 3 siting requirements. This highlights the need to consider the siting of monitoring stations on a case-by-case basis to ensure that they are representative of the AQMAs, given that AQMAs are representative of areas of exceedance.

Even where sites were considered to be representative, it was often difficult to show that implemented measures had had any positive impact on local $\mathrm{NO}_{2}$ concentrations. Traffic Urban sites in Oxford AQMA and York AQMA were not able to detect improvements in local $\mathrm{NO}_{2}$ despite the implementation of AQAPs 
which would have been expected to have had a direct impact on concentrations within the timescale under consideration. In Leicester AQMA, an absence of AQAP progress reporting meant implementation of measures could not be determined.

Some successful measures were identified, even if not directly related to the original Round 1 baseline AQMAs. The construction of the Dodworth bypass in Barnsley, for instance, was reported to have led to the direct revocation of the AQMA 2B; a rare example of an AQAP leading to an $\mathrm{NO}_{2} \mathrm{AQMA}$ revocation and in contrast with previous reviews (Moorcroft and Dore [8]). The implementation of the GBBN improvements may also have been associated with reductions in local $\mathrm{NO}_{2}$ concentrations at two sites in the Bristol AQMA, if not the A420 route, and the M32 Management measure may also have resulted in lower concentrations at associated monitoring sites. However, these must remain tentative conclusions.

In all cases (apart from the Dodworth bypass), however, it has been impossible to categorically state that any implemented AQAP measures have specifically caused a reduction in $\mathrm{NO}_{2}$ concentrations at any site. This is due to a multitude of confounding factors (e.g. traffic flow, meteorology) and other, less locationspecific AQAP measures that will all have had an impact on concentrations at both Background Urban and Traffic Urban sites. The implementation of more directly focused AQAP measures is necessary to improve air quality at specific pollution hotspots. The problem, as evidenced in the subsequent expansion of all of the original case study AQMAs, is that traffic pollution has become a much more widespread problem and less confined to discrete hotspot locations.

All of the case studies had integrated their AQAPs into their LTPs at varying stages in the process and the implementation of measures have been largely determined by the priorities of local transport officers, an issue that was highlighted in previous research (Olowoporoku et al. [11, 12]). Evidence of mandatory air quality indicators (LTP8) that were not aligned to either the national air quality objectives or the EU limit values in the Oxford AQAP/LTPs was of concern as this clearly demonstrates a lack of commitment to, or, perhaps, a tacit acknowledgement of the impossibility of achieving, the necessary reductions in $\mathrm{NO}_{2}$ concentrations required by national and EU legislation, and more fundamentally, that are required to prevent worsening of public health.

\section{Conclusion}

With reference to the research question, the key finding from this research is a confirmation of the research statement, i.e. that currently LAQM is not a successful strategy in achieving selected EU limit values. Despite the opportunity that LAQM provided to assist the government with achievement of the EU limit values, the process was never calibrated sufficiently to provide a measureable contribution. There are several factors that have been identified in this research to corroborate this statement, most relating to monitoring data and sites, but one of which is specific to Action Planning.

The requirement for local authorities to produce AQAPs (within 18 months of declaration of an AQMA) and annual AQAP PRs does not appear to have been 
effectively enforced. This research found that some local authorities that had declared AQMAs had not published AQAPs within the specified timescale or within a number of years in some cases. Similarly, progress on the AQAPs is required annually, but there was an absence of annual AQAP Progress Reports found in this study. This is perhaps one of the most significant failings, as without the ability to gauge progress on measures implemented at a local level, neither national nor local government can show whether LAQM is working to improve local air quality.

\subsection{Recommendations for improving the effectiveness of LAQM}

The following recommendations are made for Defra, and the Devolved Administrations of Scotland, Wales and Northern Ireland, to improve the effectiveness of LAQM in assisting with the achievement of the $\mathrm{NO}_{2}$ annual mean EU limit value. They are proposed as solutions to the limitations and obstacles observed in undertaking this research, in order to facilitate a combined effort both nationally and locally to reducing traffic-related nitrogen dioxide concentrations in order to achieve the EU limit value. The current revision of LAQM and the recent changes to the EU AAQD reporting requirements make this an opportune moment to instigate these proposed changes.

- Recommendation 1. Require AQAP measures to be targeted at reducing concentrations of $\mathrm{NO}_{2}$ in the area of exceedance.

- Recommendation 2. Ensure that all local authorities, that are required to, report annually on their AQAPs so that these reports can be incorporated in the UK's compliance assessment reporting.

- Recommendation 3. Standardise AQAP reporting requirements to ensure consistency of data reported to the European Commission.

In addition, the following recommendation for further research is suggested:

- Investigate a robust approach to quantification of air quality action plan measures.

\section{References}

[1] Great Britain. The Air Quality Regulations 1997 3043. London. Available from: http://www.legislation.gov.uk/uksi/1997/3043/made, 1997.

[2] Department of the Environment, The United Kingdom National Air Quality Strategy. London: DoE, 1997.

[3] Department for the Environment, Transport and the Regions, The Air Quality Strategy for England, Scotland, Wales and Northern Ireland. London: DETR, 2000.

[4] Defra (2014a). Air Pollution in the UK 2013 Compliance Assessment Summary. http://uk-air.defra.gov.uk/assets/documents/annualreport/air_ pollution_uk_2013_Compliance_Assessment_Summary.pdf.

[5] Defra (2014b). Updated projections for Nitrogen Dioxide (NO2) compliance. http://uk-air.defra.gov.uk/assets/documents/no2ten/140708_ N02_projection_tables_FINAL.pdf. 
[6] International Council on Clean Transportation Europe (ICCT) (2014). RealWorld Exhaust Emissions from Modern Diesel Cars. http://www.theicct.org/sites/default/files/publications/ICCT_PEMS-study_ diesel-cars_20141010.pdf.

[7] Localism Act 2011. Chapter 20. (2011) London: The Stationery Office.

[8] Moorcroft, S. and Dore, C., 2013. Review of Effectiveness of Local Authority Action Plans and Future Policy Options for LAQM. Report number: 1372/1/F1.Defra.

[9] Barnes, J. H., Hayes, E. T., Longhurst, J. W. S. (2013). Is Local Air Quality Management a Successful Strategy in Achieving Selected EU Limit Values, Air Pollution XXI, Siena, 5th June 2013.

[10] Barnes, J., Hayes, E. T. and Longhurst, J. (2014) Has implementation of Local Air Quality Management reduced local nitrogen dioxide concentrations in the UK? In: Air Pollution 2014: 22nd International Conference on Modelling, Monitoring and Management of Air Pollution.

[11] Olowoporoku, D., Hayes, E., Longhurst, J. and Parkhurst, G. (2011) Improving road transport-related air quality in England through joint working between Environmental Health Officers and Transport Planners. Local Environment (online). 16 (7), pp. 603-618. (Accessed 17 February 2012.)

[12] Olowoporoku, D., Hayes, E., Longhurst, J. and Parkhurst, G. (2012) The rhetoric and realities of integrating air quality into the local transport planning process in English local authorities. Journal of Environmental Management (online). 101, pp. 23-32. (Accessed 9 March 2012.) 